University for Business and Technology in Kosovo

UBT Knowledge Center

UBT International Conference

2013 UBT International Conference

Nov 2nd, 2:15 PM - 2:30 PM

\title{
Flexible Use And Aplication Of Energy Efficiency Measures In Existing Multi-Residential Buildings
}

\author{
Sadije Kelmendi \\ University for Business and Technology, sadije.kelmendi@ubt-uni.net \\ Vlora Aliu \\ University for Business and Technology, vlora.aliu@ubt-uni.net
}

Follow this and additional works at: https://knowledgecenter.ubt-uni.net/conference

Part of the Architecture Commons

\begin{abstract}
Recommended Citation
Kelmendi, Sadije and Aliu, Vlora, "Flexible Use And Aplication Of Energy Efficiency Measures In Existing Multi-Residential Buildings" (2013). UBT International Conference. 19. https://knowledgecenter.ubt-uni.net/conference/2013/all-events/19
\end{abstract}

This Event is brought to you for free and open access by the Publication and Journals at UBT Knowledge Center. It has been accepted for inclusion in UBT International Conference by an authorized administrator of UBT Knowledge Center. For more information, please contact knowledge.center@ubt-uni.net. 


\title{
Flexible Use And Aplication Of Energy Efficiency Measures In Existing Multi-Residential Buildings
}

\author{
SadijeKelmendi ${ }^{1}$, Vlora Aliu ${ }^{2}$ \\ ${ }^{1,2}$ University for Business and Technology \\ Department of Architecture and Spatial Planning, Prishtina. Kosovo \\ e-mail: sadije.kelmendi@ubt-uni.net \\ e-mail: vlora.aliu@ubt-uni.net
}

\begin{abstract}
Recent trends in energy efficiency around the world and implementation of flexible housing are taking a big burst of development. Nanotechnology and thermal insulation materials along with photovoltaic panels will be explored in residential facilities. Needs for higher comfort and the socio-economic situation ask for research, use of eco systems and innovative solutions. The case study will be the collective residential building near the Swiss Diamond Hotel in Mother Teresa Square in Prishtina. Some of the proposed interventions will be manoeuvrings with flexible housing units, intervention on the facade with the nanotechnology insulating material as well as covering one part of the facility with photovoltaic panels. This research is based on analysing the location, facility use, orientation, surrounding site. The proposed concepts are in complete harmony with the reasonabilityof the investment. Applying these measures, besides economic, ecological and comfort benefits will also affect the adaptation of the building with the surrounding buildings.
\end{abstract}

Keywords: energy efficiency, nanotechnology, photovoltaic panels, flexible housing.

\section{Introduction}

The road toward the sustainability, as new and essential paradigm of our society, should drive us to a search of the reduction of the energy consumption, as well as the increase of the energy efficiency in our buildings, in combination with the substitution of fossil energy for renewable energy.

Global challenges these days are:

- Half the world's people now live in towns and cities. In little more than a generation, two-thirds of the global population will be urban.

- $\quad$ Rapid urbanization, (XIX cent $=2 \%$, XX cent $=10 \%$, XXI cent $=50 \%$ 2050=70\%)

While the same trend continues in Kosovo, too. $39.1 \%$ of Kosovo inhabitants live in urban areas, whereas $61 \%$ live in rural ones.

As the proportion of humanity living in the urban environment grows, so too does the need to strengthen the urban focus of our efforts to reduce global poverty and promote sustainable development.

One of the main factors how one can promote sustainable development is to develop new building designs in a sustainable manner. The reasons are listed below:

- $\quad$ Buildings consume more energy than any other sector

- Buildings are the largest contributor to climate change

- $\quad$ The health of the global economy is tied to the building sector

The majority of the building were constructed about 30 years ago and apart from the ageing of the façade, roof and windows, the building standards and material quality regarding energy saving at that time were significantly lower compared to the one today. 


\subsection{Objective}

The aim of this research is to apply and test new and innovative technologies to promote integrated environmental protection in harmony with architectural design.

Main objectives of this study are:

- To demonstrate that flexible, energy-efficient, sustainable residential buildings can meet fully the architectural, functional, visual and thermal comfort, control and safety requirements.

- To provide better conditions in terms of thermal comfort, airquality, day lighting and a coustics. Use healthy, environmentally friendly and renewable materials.

\subsection{Existing situation of the facility}

The facility is located near Mother Teresa Square and connecting secondary road, has a very good orientation, mainly east, south and west.

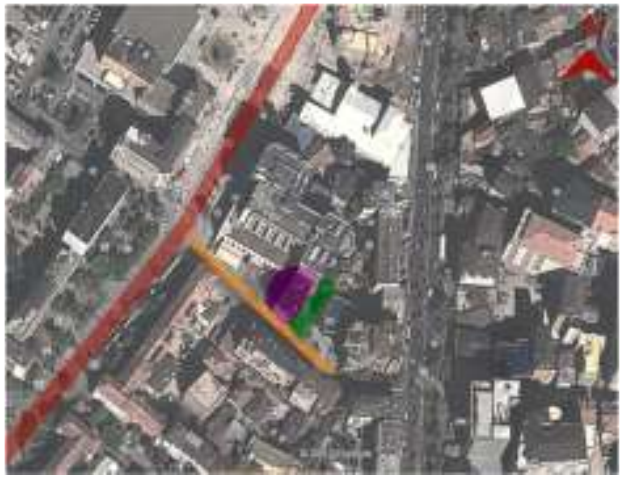

Fig.1. Orthophoto of building location and acces to it

\subsection{Architectural characteristics of the building}

The building is 5 floors high, while the groundfloor for the moment is used for shops and offices and four other floors contain housing. It is visible that all facades are treated after the war, mainly with new windows in residential part while there is no diversity of facade and fits very well with surrounding residential buildings.

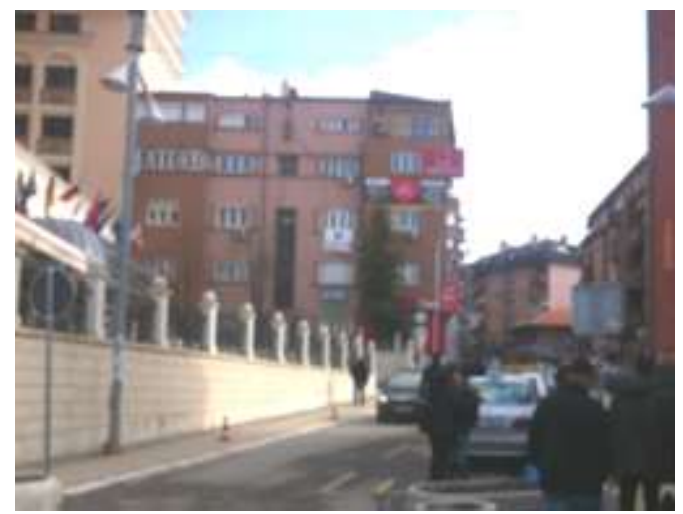

Fig.2. View of the existing building 


\section{Improvements}

The reason for intervention - changing the apartments in the flexible ones has derived as a reason to economize and to have a more rational utilization by different ages visitors.

The location of the building with residential units is the key reason for flexible apartments maneuverability.

\subsection{Architectural improvements}

Due to the constraints such as location, surrounding and road which also seves as access to the prestigious hotel in the city of Pristina, there is no possibility to increase or utilize neighbo ring parcels and therefore the contours and dimensions of the building are kept.

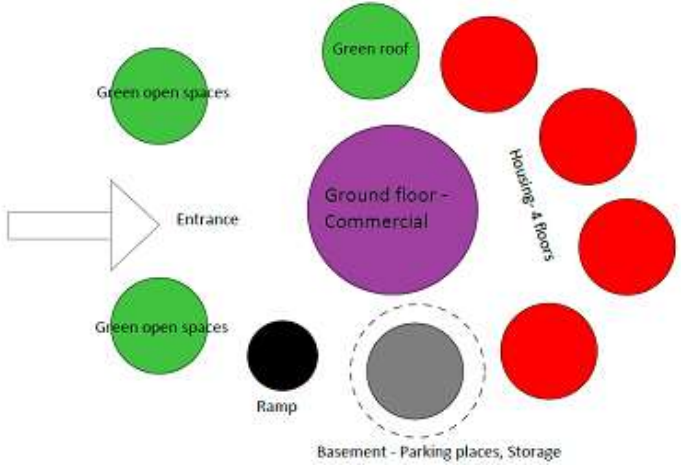

Fig.3. Concept of functions connecting in the building

However, most contents inside the building are changed, starting from building walls, residential rooms, also the floor which is used for shops and offices, as well as basement which is proposed to be used for parking lots and apartments' storages where is designed a ramp for the access to basement which has not previously existed. Due to the vicinity of Swiss Diamond Hotel and ts high cost, it is proposed to convert these flats into more flexible, where the visitor will be able to stay at a lower cost and at the same time to be located at the center of the city of Pristina.

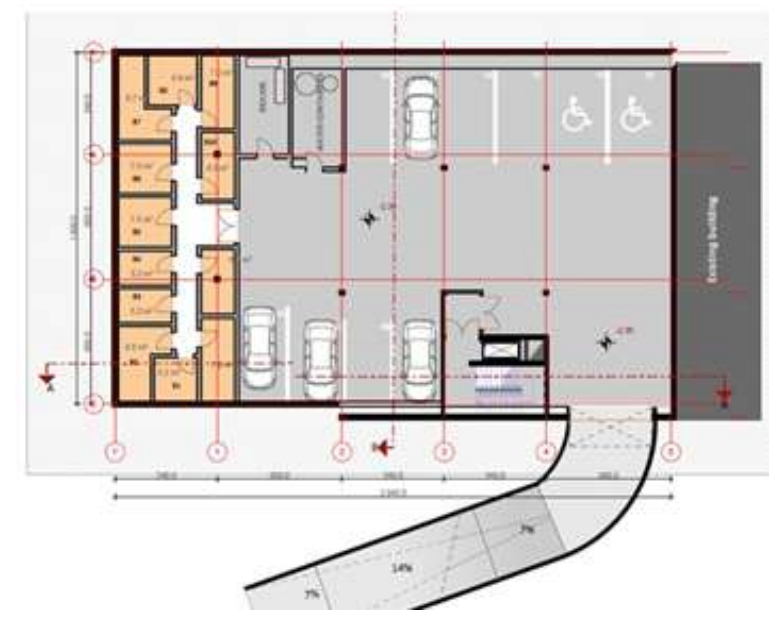

Fig.4. Bas ement reorganization of functions

In this floor is presented the basement which is completely reorganized in the new feature, in which are proposed storages for each apartment, as well as water containers and heating boilers while not overlooking the parking places for the number of users as well as parking places for people with special needs. 


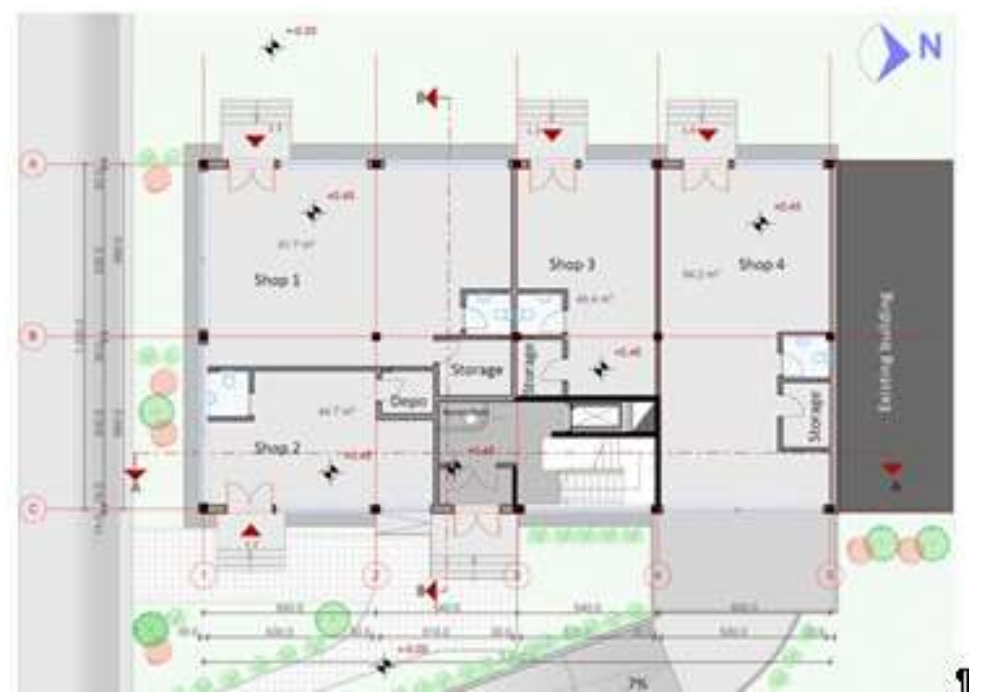

Fig.5. Groundfloor reorganization of functions

In this drawing is presented the ground floor which is modified from the one it was existing. Due to the fact that this building has a good position in the city center, it is proposed to transform the whole groundfloor to shops and offices. What is preserved is the construction systemand sanitary nodes. The main entrance to the building was saved from the existing situation.

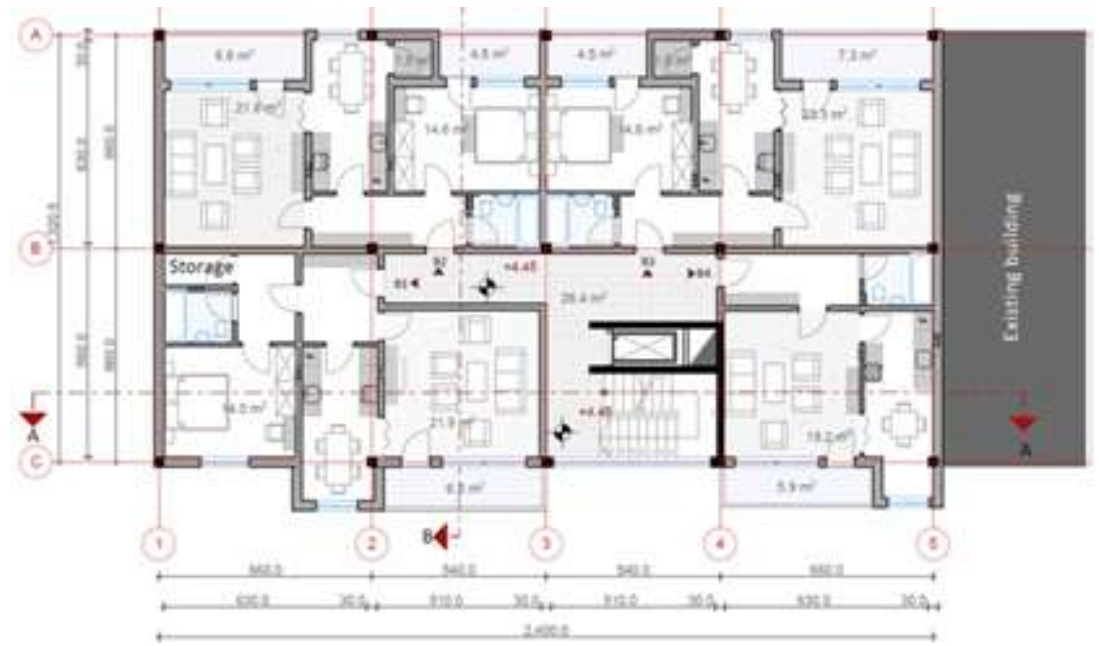

Fig.6. First floor proposed reorganization with flexible apartments

The concept of flexible units means that organization and size of apartment units varies in floors, ie all residential floors change as perthe function, except the construction, the core, and sanitary nodes, which remain the same. 


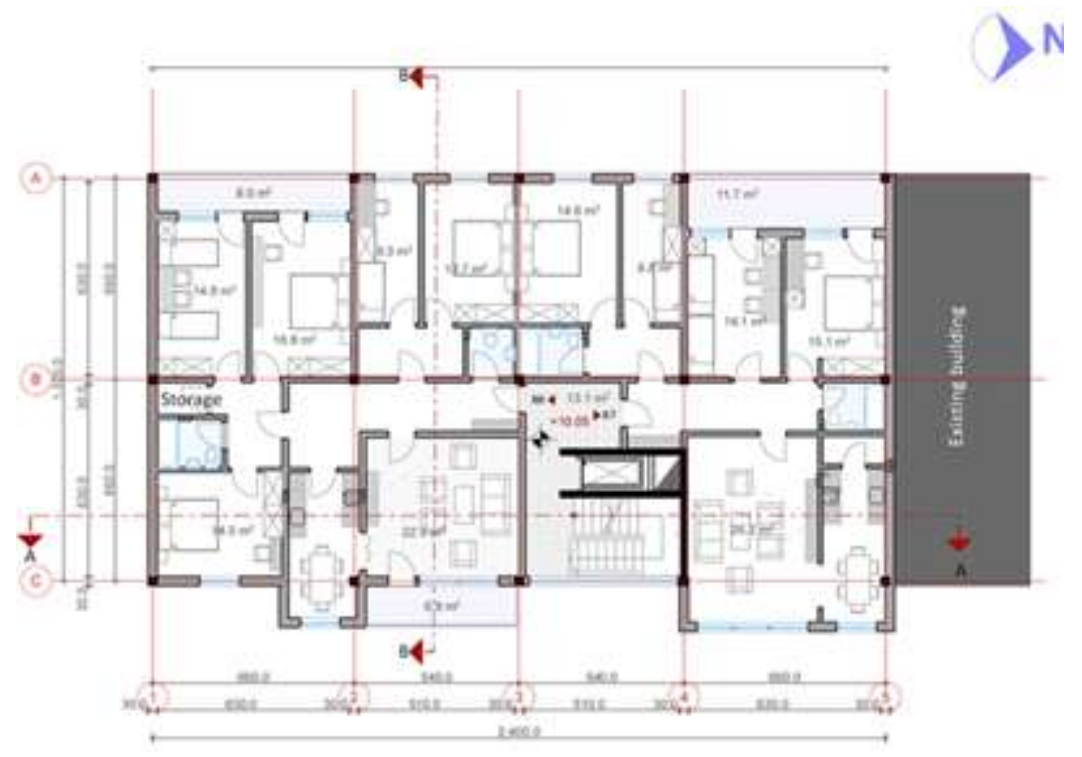

Fig.7 Second floor proposed reorganization with flexible apartments

So with the new design, the first floor has 4 apartments in total, 2nd floor has 2 apartments, 3rd floor 2 apartments and 4 th floor has 4 ones.

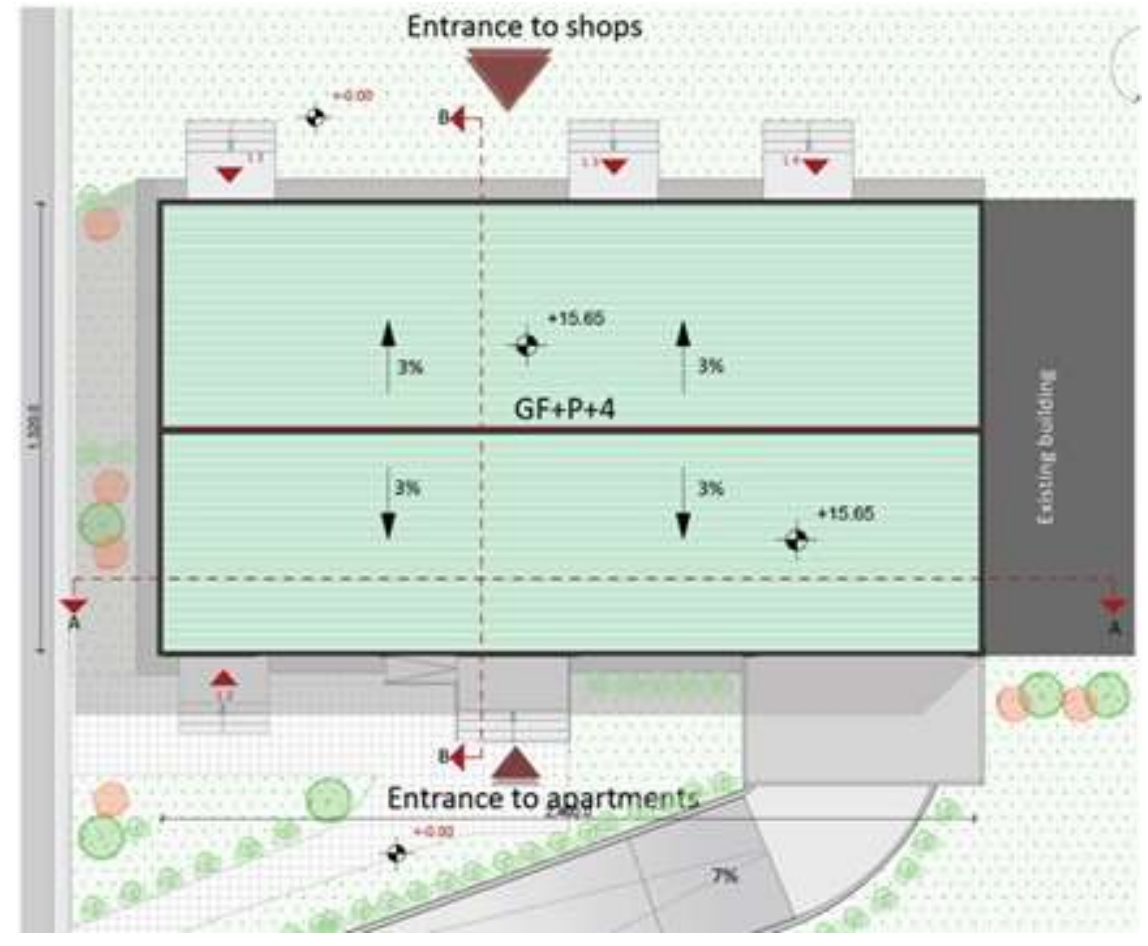

Fig.8. Proposed roof floor plan

\subsection{Energy efficiency improvements}

First of all, we need to determine on which category is this object going to belong. According to European Standards for overall level of energy outgoing the object can be categorized this way:

- Low Energy House, (,Niedrigenergiehaus"): $\max .70 \mathrm{kWh} / \mathrm{m}^{2} \mathrm{a}$

- Passive House: $\max \underline{15 \mathrm{kWh} / \mathrm{m}^{2} \mathrm{a}}$ 
- Zero-Energy-House: no energy demand (calculated over the year)

- Plus-Energy-House: produces more energy than it requires (calculated over the year)

The first category (Low Energy House) is the class we are trying to achieve on this object which means that with the improvements and interventions we should reduce the energy outgoing rate in max $\underline{70}$ $\mathrm{kWh} / \mathrm{m}^{2} \mathrm{a}$

With the aim to reduce the $\mathrm{CO} 2$ emission of the building and to minimize the heat losses, it is proposed to close the building envelope.

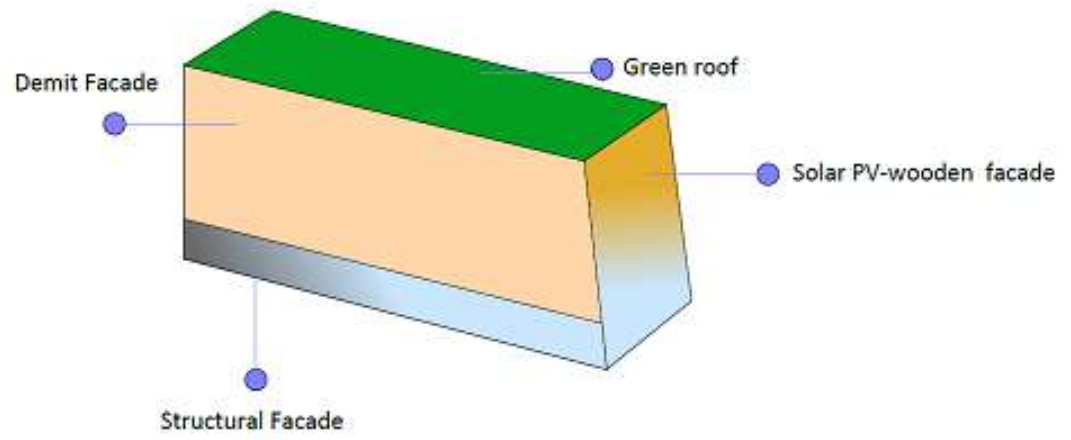

Fig.9. Materials used for building envelope

\subsection{Insulation of the walls and roofs}

The easiest, fastest and the most effective way to reduce costs of heating - and also of cooling in summer - is to apply a suitable thermal insulating protection. It is proposed to apply insulation and color materials which are environmentally friendly because they will also help to reduce the buildings carbon footprint.

It is proposed to insulate roof and to cover it with layers of green roof, which has many positive attributes and does not burden the weight of the roof construction. Below are some of the green roof layers that are appropriate in residential facilities.

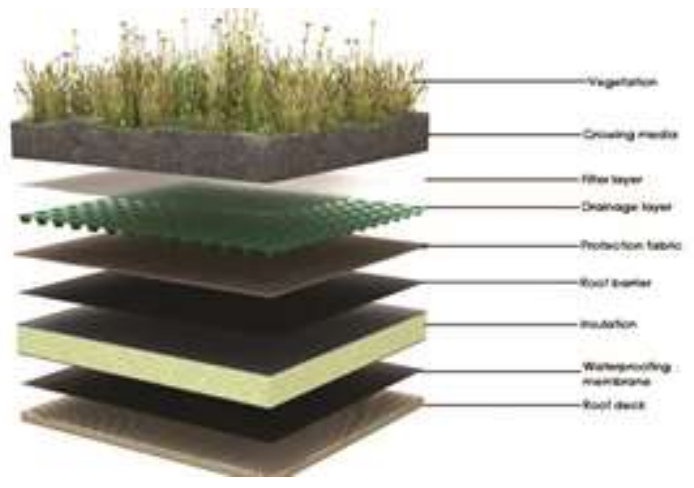

Fig.10. Green roof layers

Existing facade was changed because of the architecture and use of materials with new technologies and adaptation to surrounding objects.

Regarding the facades we have used structural facade on the ground floor where its use is commercial while a the residential floors are proposed to be treated and insulated with nano-technology material for facade. 


\subsection{Insulation with nano-technology material}

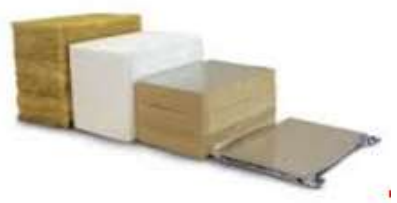

Fig.11. Width of nano-technology insulation compared to other insulation materials

This material contains approximately 70\% Hydro-NM-Oxide and 30\% acrylic resin and performance additive. A liquid applied coating, it dries to a thin layer and provides exceptional insulation, corrosion protection, prevents mold, and prevents rust. Nansulate has proven to provide energy savings in a variety of industrial and residential insulation application.

\subsection{PV panels in combination to wooden panels}

In order to increase the efficiency of the building, it is proposed to install new photovoltaic panels on the facade.

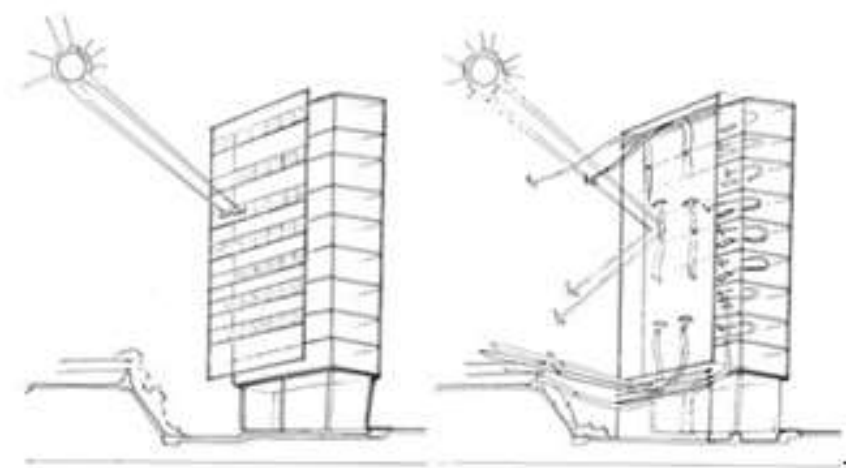

Fig.11 Structural-Double skin facade (Source: Innovations in Façade Technology-Context in UK)

Double-skin façade is a system in which two "skins" - two layers of glass - are separated by a significant amount of air space, that is to say, a second glass façade is placed in front of the first. These two sheets of glass act as an insulation between the outside and inside enabling the air to circulate between the cavity of the two facades skin providing good air circulation, thermal and accoustic performance.

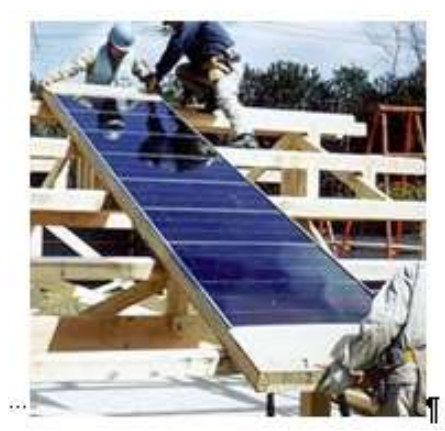

Fig.12. Photovoltaic panels

The southern facade is proposed to be covered with solar PV panels (Building Integrated Photovoltaic or BIPV in short) is also off the residence that overlooks the main road and this facade is combined with wood because of the production of electricity from sun and for reasons of architecture. This facade is placed in vertical angle of 15 degrees. Sufficient ventilation space behind array is designed for cooling purposes. Semi-transparent glass/glass Photovoltaic modules were used in balconies. The Photovoltaic 
integrated balustrade has enhanced the facade design whilst ensuring safety of the occupants and energy generation. They are also perfect in allowing good visibility whilst protecting privacy.

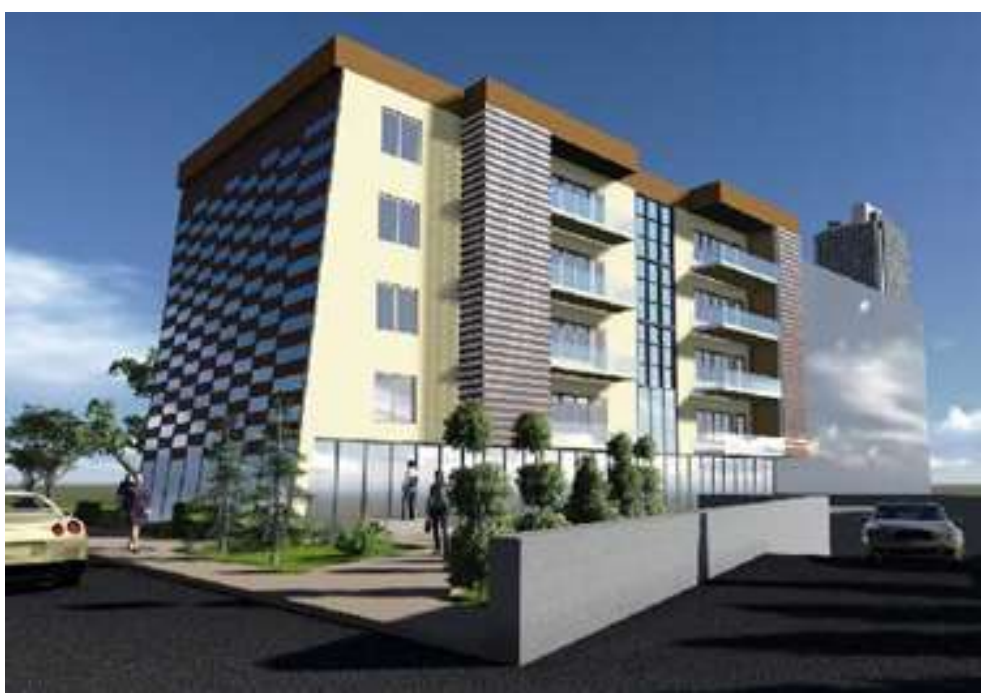

Fig.15 vizualization of proposed building envelope

\subsection{Energy Performance Evaluation}

Analysis done to inspect the existing situation is multi-disciplinary. Simulation software used to generate data for $\mathrm{U}$ value and energy demand is Ecodesigner, a Graphisoft ArchiCAD add-on. EcoDesigner enables architects to compare energy consumptions, monthly energy balances, operation costs, carbon emissions and other indicators to inform the design process and make the best design choices - regardless of the climate where the building is built or renovated.

\begin{tabular}{|c|c|c|c|c|c|c|c|c|c|c|c|}
\hline Locabion b Function & & Sructures 4 & Opene & ang ! & MEPSY & stementin & $n s$ Energy $G$ & Green Energy & & & \\
\hline \multicolumn{12}{|c|}{ Cperings on bulding shel: } \\
\hline Orientabion & & Opening tys & & Aves & $\left.\left[m^{2}\right]\right]$ & & Shading dev.... & .. Glass \% & Uvaduxt... & $15 T \%$ & Inforab... \\
\hline Noth & 世 & Whow & & 16 & & - & Nane & . 80 & 1 & 53 & 1 \\
\hline East & 且 & Door & & 2 & & & tore & 60 & 1 & 53 & 1 \\
\hline South & 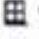 & Window & & 49 & & & None & 60 & 1 & 53 & 1 \\
\hline Eost & 田 & Whdow & & 82 & & & None & 60 & 1 & 50 & 1 \\
\hline North & 且 & Door & & 7 & & & None & 80 & 1 & 53 & 1 \\
\hline South & 且 & Door & & 14 & & & None & 80 & 1 & 53 & 1 \\
\hline West & 田 & Wholow & & 92 & & & Gutan & 75 & 3 & 66 & 4 \\
\hline
\end{tabular}

Figure 16. Data input table in Ecodesigner

From the Ecodesigner graphics below, it can be seen that the proposed interventions would result in energy consumption reduction of $169 \mathrm{kwh} / \mathrm{m}^{2}$ a (from 231 to 62), which also influences the $\mathrm{CO}_{2}$ reduction.

This intervention would bring this building from a conventional building standard to Low-Energy House standard. 


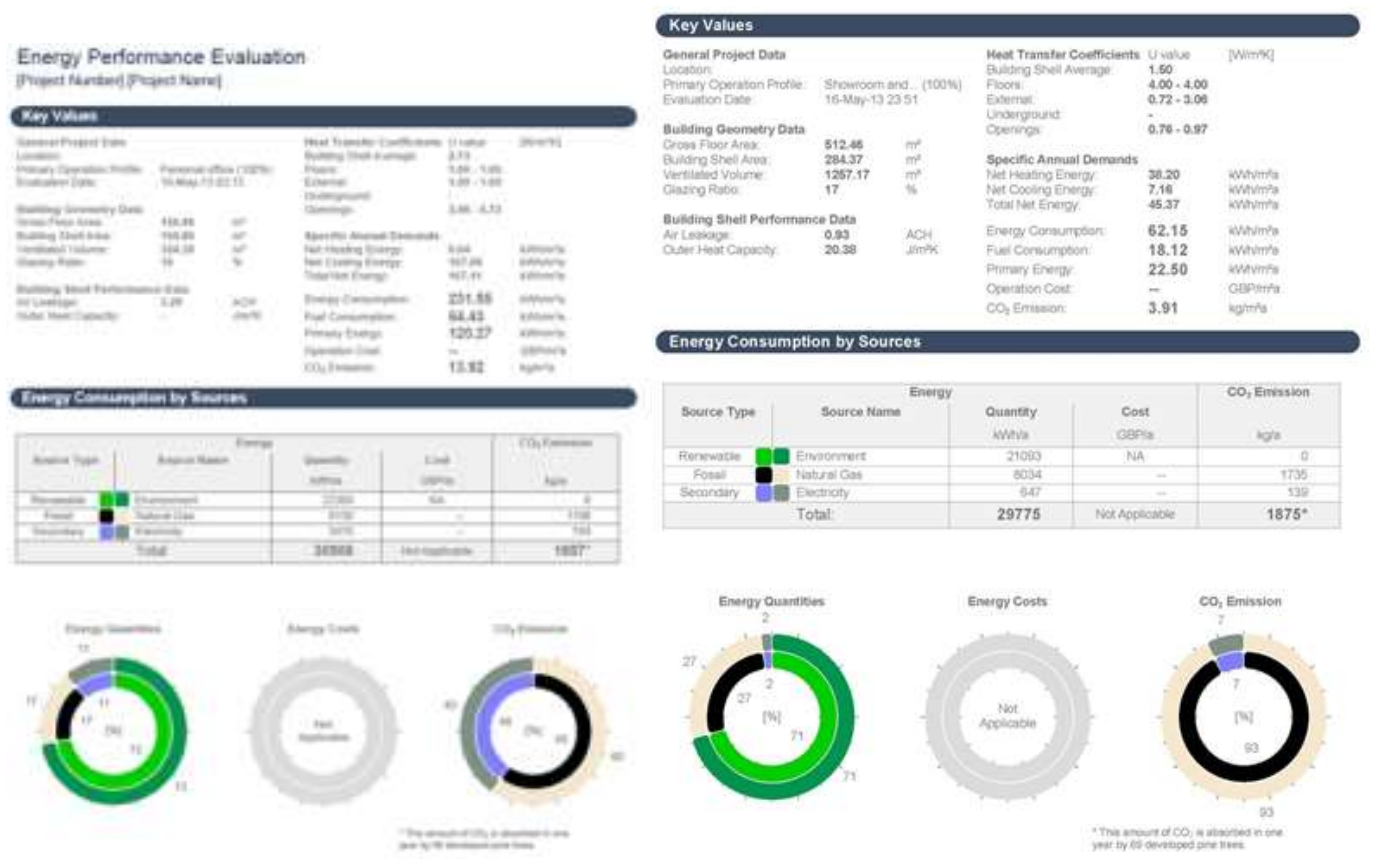

Figure 17. Energy evaluation of building model before and after the improvements

\section{Conclusions}

With the recommended interventions we would achieve:

- Improvements of comfort inside the building for the work staff and visitors.

- The ability of working during the winter which would also increase the number of the visitors

- A good example to rise the public awareness about sustain and ecologic building.

- After compensating the investment value the building would continue to function with minimal operative cost

- $\quad$ The decrease of $\mathrm{CO} 2$ level in nature

- The decrease of energy consume

- The accomplishment of the $9 \%$ energy threshold determined by PKEE

\section{References}

1. Sadije KELMENDI, Sustainable Renovation of public buildings in Kosova-Case Study: Kindergarten Fatosat. In Proceedings of the International Conference of Architecture and Spatial Planning, Prishtina, University for Business and Technology, pp. 130-140.

2. Price Myers (2004). Sustaining tower blocks, http://singleaspect.org.uk/sustower/SOApresent.htm, [accessed 15.08.2013]

3. Building and construction authority (. Green handbook-Photovoltaic (PV) systems in buildings, http://www.bca.gov.sg/GreenMark/others/pv_guide.pdf, [accessed 10.10.2013]

4. The Public Arts Centre, West Bromwich, United Kingdom, "Energy Efficiency and Sustainability in Retrofitted and New Museum Buildings Handbook” University College Dublin, 2004, Ireland pp.156. 